\title{
Ceramic products obtained from rock wastes
}

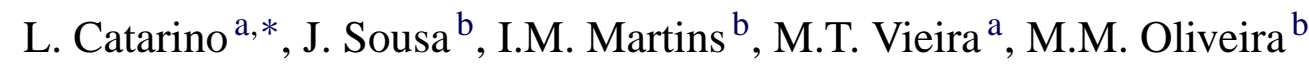 \\ a ICEMS, Department of Mechanical Engineering, Univ. Coimbra, Polo II, 3030-201 Coimbra, Portugal \\ ${ }^{\mathrm{b}}$ INETI, Department of Materials and Production Technologies, Lumiar, 1649-038 Lisbon, Portugal
}

\begin{abstract}
Residue powders resulting from cutting and machining operations in slate quarries were processed by a press and sintering route to manufacture ceramic products such as flooring and roofing tiles. The first part of this work consisted of a laboratory study carried out by uniaxially pressing the powders to shape and sintering in air using a muffle type furnace. A plan of sintering experiments was followed in order to evaluate the effect of some processing parameters: particle size distribution of the rock waste powders, compacting pressure and sintering cycle (heating and cooling rates, sintering temperature). The sintering tests have shown that the density of the sintered specimens increased gradually up to $1150-1170{ }^{\circ} \mathrm{C}$ and then started decreasing. The second stage of this study was carried out at an industrial scale. Since particle size of the raw material was found to be an important parameter, atomisation was used to homogenise the particle dimensions and ensure proper feeding of the pressing systems. Moreover, atomisation is the best way to treat very fine wastes, both for economical and technical reasons. Tiles with the dimensions $200 \mathrm{~mm} \times 100 \mathrm{~mm} \times 7 \mathrm{~mm}$ were then uniaxially pressed at $40 \mathrm{MPa}$ and subsequently sintered at temperatures close to $1150{ }^{\circ} \mathrm{C}$. The properties of the products obtained are suitable for flooring tiles.
\end{abstract}

(C) 2003 Elsevier Science B.V. All rights reserved.

\section{Introduction}

Rock wastes such as residue powders which result from cutting and machining operations in the slate quarries have a significant and serious impact on the environment. Processing these powders by pressing and sintering may be a solution for their recovery and recycling, as long as the phase transformations taking place during the sintering cycle give rise to new constituents with technological applicability. Since slates are complex materials, it is expected that the sintering mechanisms involved are also complicated: liquid phases formed will help the consolidation of the material, while liberation of gases may originate porosity. To obtain adequate microstructures for subsequent applications, optimisation of the sintering cycle is necessary. This work describes the tests carried out with slate powders in order to obtain ceramic products such as flooring and roofing tiles.

\section{Experimental}

The powders were physically characterised by determinations of particle size distribution and compressibility. Their composition was evaluated by chemical analysis and X-ray

\footnotetext{
* Corresponding author.
}

diffraction (XRD). The XRD tests were carried out with a Rigaku diffractometer, using a monochromatic $\mathrm{Cu} \mathrm{K} \alpha$ radiation and a scanning angular speed of $2^{\circ} \mathrm{min}^{-1}$.

For the laboratory scale sintering tests, the powders were uniaxially pressed to obtain rectangular specimens and sintered in air using a muffle type furnace. All samples were measured before and after sintering, to determine dimensional variations and also apparent and true density. The sintered samples were further characterised by XRD, optical and scanning microscopy and mechanical testing (three point bend tests), in order to compare their properties with current ceramic products. The three point bend tests were performed using a tensile test machine and applying the ISO standard 10545-4; the cross-head speed was $0.1 \mathrm{~cm} \mathrm{~min}^{-1}$.

The second stage of this study was carried out at an industrial scale. Since particle size of the raw material was found to be an important parameter, atomisation was used to homogenise the particle dimensions and ensure proper feeding of the pressing systems. Moreover, atomisation is the best way to treat very fine wastes, both for economical and technical reasons. Floor tiles with the dimensions $200 \mathrm{~mm} \times 100 \mathrm{~mm} \times 7 \mathrm{~mm}$ or $200 \mathrm{~mm} \times 200 \mathrm{~mm} \times 7 \mathrm{~mm}$ were then uniaxially pressed at $40 \mathrm{MPa}$ and subsequently sintered at temperatures close to $1150^{\circ} \mathrm{C}$.

The samples obtained were characterised when possible using the International Standard ISO 10545 Ceramic tiles. 
The characteristics determined were: bulk density, by the Archimedes method; true density, which was measured in a helium picnometer (Micromeritics Accupyc 1330); water absorption, by the standard ISO 10545-3:1995(E); bend strength by ISO 10545-4:1994(E), using 12 specimens with the dimensions $170 \mathrm{~mm} \times 5 \mathrm{~mm} \times 1 \mathrm{~mm}$.

\section{Results and discussion}

\subsection{Raw material}

The chemical composition of the slate powder consists mainly of $\mathrm{SiO}_{2}(50-60 \%)$ and $\mathrm{Al}_{2} \mathrm{O}_{3}(20-25 \%)$ [1]. The XRD tests of the powder have shown peaks corresponding to the following constituents: quartz, hematite, chlorite and muscovite [2].

The slate powder was subsequently sieved and the $<250 \mu \mathrm{m}$ fraction separated and used for all the tests referred to in this work. The median particle size determined for that fraction was close to $10 \mu \mathrm{m}$ (Table 1 and Fig. 1). The compressibility of the slate powder was evaluated by uniaxially pressing cylindrical specimens at different pressures and determining their geometric density. It was found that, at $40 \mathrm{MPa}$, the powder compact had already enough strength for handling, and thus this was the pressure used in all further tests.

\subsection{Laboratory tests}

The sintering tests (Fig. 2) were carried out using the following cycle, based on previous experience [1]: heating

Table 1

Parameters of particle size distribution

\begin{tabular}{lr}
\hline$d_{10}(\mu \mathrm{m})$ & 1.86 \\
$d_{50}(\mu \mathrm{m})$ & 10.46 \\
$d_{90}(\mu \mathrm{m})$ & 54.71 \\
\hline
\end{tabular}

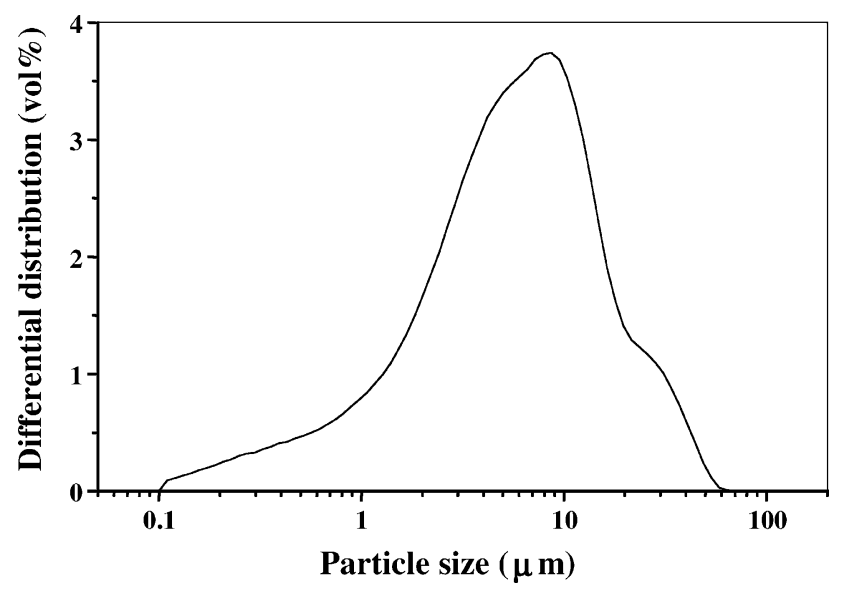

Fig. 1. Differential distribution of slate particles.

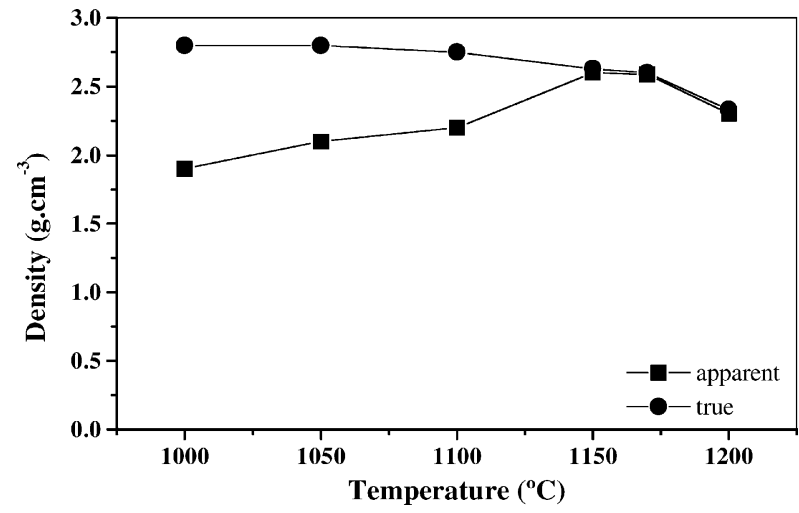

Fig. 2. Sinterability of the slate powder.

rate, $5{ }^{\circ} \mathrm{C} \min ^{-1}$; time at temperature, $30 \mathrm{~min}$; cooling rate, furnace cool.

As observed in Fig. 2, a gradual increase of the apparent density of the sintered specimens is observed to a maximum of $1150^{\circ} \mathrm{C}$. At this temperature, the values of true and apparent density are nearly the same.

Sintering tests carried out at the higher heating rate of $20^{\circ} \mathrm{C} \mathrm{min}^{-1}$ did not show significant changes in properties of the specimens. This higher heating rate, less time consuming, was therefore used in all further sintering tests carried out in the laboratory.

During sintering, several phase transformations occur in the minerals present in slate powders and the ultimate phases obtained are mainly mullite and a glassy phase.

The selection of sintering temperatures near to $1150^{\circ} \mathrm{C}$ was a compromise between the composition phases and all the properties analysed in different samples.

The results shown in Table 2 indicate that the slate powders, sintered at 1150 and $1170{ }^{\circ} \mathrm{C}$, yield a strong and reliable material.

A typical microstructure of sintered slate powder is shown in Fig. 3. Observations were complemented by SEM with EDS. The grey background is mainly glassy phase, the white areas were identified as mullite and the dark zones are phases with iron and aluminium. It should be noted that mullite is a phase also obtained by heat treatment of kaolinite [3], which is a main constituent of clays. However, the presence of glassy phase in products resulting from slate wastes induce higher performances than those obtained from the clays currently used for flooring tiles.

Table 2

Properties of sintered samples

\begin{tabular}{lcc}
\hline & \multicolumn{2}{c}{ Sintering temperature $\left({ }^{\circ} \mathrm{C}\right)$} \\
\cline { 2 - 3 } & 1150 & 1170 \\
\hline Sintering time $(\mathrm{min})$ & 30 & 30 \\
True density $\left(\mathrm{g} \mathrm{cm}^{-3}\right)$ & 2.6 & 2.6 \\
Shrinkage $(\%)$ & 8.1 & 10.2 \\
Bend strength (MPa) & 75 & 92 \\
Weibull modulus & 14 & 25 \\
\hline
\end{tabular}




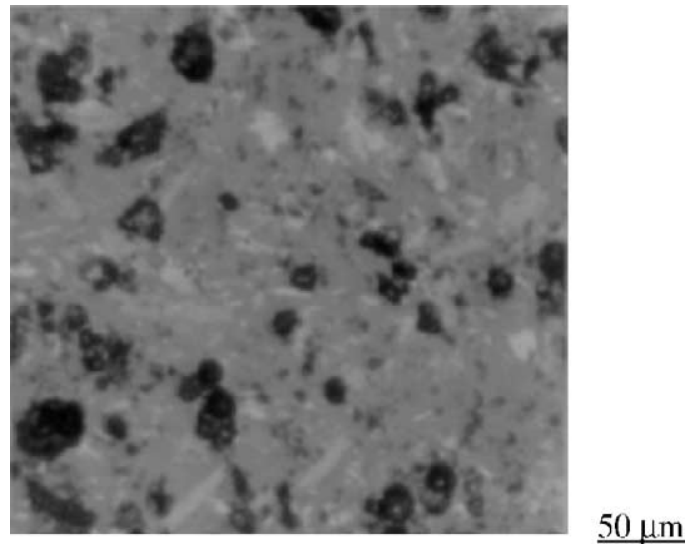

Fig. 3. Typical microstructure of the sintered slate powder: the grey background is mainly glassy phase, with white areas of mullite and dark zones with iron and aluminium.

XRD determinations by a quantitative method [4] gave indications on the amounts of glassy phase (56\%) and mullite $(20 \%)$.

\subsection{Industrial tests}

In the transference of know-how from the laboratory to the industry, there are several problems to solve. In the case of the forming by pressing, the most important of them were water content and pressure of compaction.

The addition of water to powders is a practice in the ceramic industry. In fact this is a traditional solution to increase the plasticity and the green strength of the clay-based product.

The particle size of the powders of slate wastes used $(\sim 10 \mu \mathrm{m})$ is very low and during the pressing operation a dust atmosphere is formed in the plant. The dimensions of the particles should therefore be increased and thus atomisation must be used for industrial processing. After a previous study concerning selection of the best defloculant, the powder was spray dried. The atomised particles had a median particle size close to $300 \mu \mathrm{m}$ (Table 3 and Fig. 4).

In order to compare the larger samples $(200 \mathrm{~mm} \times$ $100 \mathrm{~mm} \times 7 \mathrm{~mm}$ ) obtained in the plant, using production kiln, with those obtained in the laboratory $(100 \mathrm{~mm} \times$ $50 \mathrm{~mm} \times 5 \mathrm{~mm}$ ), some mechanical properties were tested. The properties evaluated were bending strength, water absorption, density and shrinkage (Table 4).

The mean value obtained for bending strength was $52 \mathrm{MPa}$. This value is lower than the obtained in laboratory samples ( $75 \mathrm{MPa}$ ) but higher than the minimum requested.

In case of water absorption, density and shrinkage, the mean values were similar to those obtained in laboratory

Table 3

Parameters of particle size distribution of slate powder after spray drying

\begin{tabular}{ll}
\hline$d_{10}(\mu \mathrm{m})$ & 220.0 \\
$d_{50}(\mu \mathrm{m})$ & 322.5 \\
$d_{90}(\mu \mathrm{m})$ & 414.5 \\
\hline
\end{tabular}

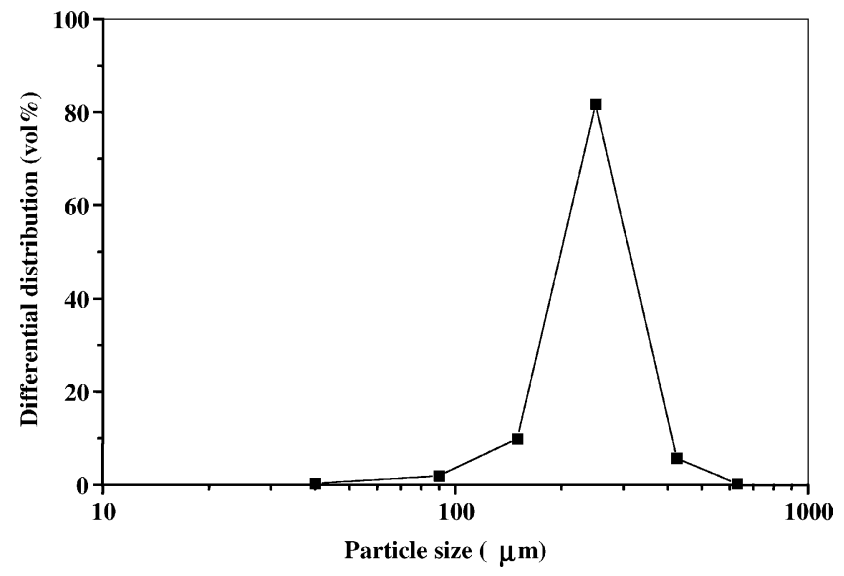

Fig. 4. Differential distribution of atomised particles.

Table 4

Properties after laboratory and industrial processing

\begin{tabular}{lccc}
\hline Properties & Required & Laboratory tests & Industrial tests \\
\hline Density $\left(\mathrm{g} \mathrm{cm}^{-3}\right)$ & - & 2.6 & 2.5 \\
Shrinkage $(\%)$ & $\sim 8.5$ & 8.1 & 9.6 \\
Water absorption (\%) & $<0.5$ & 0.02 & 0.05 \\
Bend strength (MPa) & $>27$ & 75 & 52 \\
Weibull modulus & - & 14 & 5 \\
\hline
\end{tabular}

samples. The industrial samples have, however, more porosity than the laboratory ones, which is revealed by the lower density and higher water absorption and also explains the lower value of the Weibull modulus.

\section{Conclusions}

Manufacturing ceramic tiles from slate wastes give rise to products with better properties than those obtained in ceramic tiles manufactured from clay. By using this raw material, it is possible to solve two problems: the elimination of large quantities of wastes and the improvement of the mechanical performance of the ordinary tiles used in building construction.

\section{Acknowledgements}

This investigation was financed by the CRAFT contract BRST-CT97-5125, "Recovery of Slate wastes".

\section{References}

[1] M.T. Vieira, L. Catarino, M. Oliveira, J.M. Torralba, L.E.G. Cambronero, F.L. González-Mesones, A. Victoria, J. Mater. Process. Technol. 92-93 (1999) 97.

[2] M.T. Vieira, L. Catarino, J.P. Dias, M. Oliveira, J. Sousa, J.M. Torralba, M.C. Gomez, L. Cambronero, F. Gonzalez-Mesones, M. Rodrigues, Proceedings of the UROTHEN 2000 Workshop, vol. 1, 2000, p. 375.

[3] A. Gualtieri, M. Bellotto, G. Artioli, S.M. Clark, Phys. Chem. Miner. 22 (4) (1995) 215.

[4] J.F. Bartolomé, Bol. Soc. Esp. Ceram. Vídrio 35 (4) (1986) 271. 